\title{
A Study of the effects of Busan Leading Company Certification on Business Performance
}

\author{
Ju-Wan Kim', Young-Seok Ock ${ }^{2}$ \\ ${ }^{1}$ General Affairs Team/Busan TechnoPark \\ 138-2, Eomgung-dong, Sasang-gu, Busan Metropolitan City, Republic of Korea \\ kjw@btp.or.kr \\ ${ }^{2}$ Graduate School of Management of Technology/Pukyong National University \\ 365 Sinseon-ro Nam-gu, Busan Metropolitan City, Republic of Korea \\ ysock@pknu.ac.kr
}

\section{Extended Abstract}

Recently, in spite of the global economic crisis, small and medium-sized enterprises (SMEs) with strong technological capabilities are showing steady growth. SMEs that actively respond to uncertain global economic flows play an important role in revitalizing the local economy. So it was necessary to make an echo system in which SMEs can grow well and to provide an efficient support system suitable to the growth stages of regional global small-giant enterprises.

There are some researches about the effect of the support policies for the SMEs. In order for the regional SMEs to be the global hidden champion, the government should support SMEs to promote product innovation and construct the knowledge management system in [1]. To foster the goals of growth of SMES, core competencies that SMEs will become Small Giant enterprises was analysed in [2]. The performance of the World Class 300 project as the key part of the support policy for SMEs by categorizing it into output and outcome according to the program logics model in [3]. The effects of corporate strategy, business ethics, knowledge management on business performance of leading companies in Busan in [4]. The effectiveness on the regional policy in Busan was analysed by the corporate performance in [5].

The purpose of this study is to evaluate the effectiveness of the support program (especially leading company certification) for the SMEs in the local area, Busan. The effect of the leading company certification in Busan on business performance is analysed. From 2006, Busan leading company certification was designed to foster the competitiveness of SMEs and SMEs to become global small-giant enterprises and lead the economic growth in Busan. In order to analyse the effect of leading company certification on business performance, the empirical analysis by the financial factors of company was performed and the business performance of leading companies was verified.

As a result of the analysis, there is a positive (+) relationship between the certification and the business performance of leading companies. As the specific factors, the business performance in the company size, sales, export proportion, industry type, and R\&D ratio showed a positive (+) relationship in the manufacturing industry.

\section{References}

[1] S. M. Kang, "A Study on Support of Regional Small and Medium Sized Firms for Making Global Hidden Champion," J. International Studies, vol. 28, pp. 117-131, 2018.

[2] W. J. Park and K. H. Park, "An Empirical Study on the Core Competences for Development of Global Small Giant Companies,” J. Society of Korea Industrial and Systems Eng., vol. 35, no. 4, pp 202-210, 2012.

[3] J. H. Choe, S. H. Yoo and H. S. Cho, "Performance Analysis of Support Policies for Small and Medium-sized Enterprises: Focusing on the World Class 300 Project," Productivity Review, vol. 30, no. 1, pp 103-132, 2016.

[4] J. H. Yoon, "A Study of the Effects of Corporate Strategy, Business Ethics and Knowledge Management on Organizational Performances of Leading Companies in Busan," J. Industrial Economics and Business, vol. 23, no. 3, pp. 1297-1319, 2010. 
[5] J. R. Cho, S. Y. Ock and Y. S. Ock, "A Study of the Effectiveness on the Regional Policy By the Corporate Performance Analysis in Busan," in Proceedings of the $8^{\text {th }}$ International Conference on Mechanics and Industrial Engineering, Madrid, Spain, 2018 